\title{
Interpretation of stress variation in silicon nitride films deposited by electron cyclotron resonance plasma
}

\author{
M. P. Besland ${ }^{\text {a) }}$ and M. Lapeyrade \\ LEOM, UMR CNRS 5512, Ecole Centrale de Lyon, BP 163, 69131, Ecully, Cedex, France \\ F. Delmotte \\ Laboratoire Charles Fabry de l'institut d'Optique, Université Paris XI, BP 147, 91403, Orsay, France \\ G. Hollinger \\ LEOM - UMR CNRS 5512, Ecole Centrale de Lyon, BP 163, 69131, Ecully, Cedex, France
}

(Received 19 November 2003; accepted 1 June 2004; published 20 September 2004)

\begin{abstract}
We report here on internal stress variations in $\mathrm{SiN}_{x}$ films deposited on silicon by plasma enhanced chemical vapor deposition-electron cyclotron resonance (PECVD-ECR) plasma. The effects of deposition parameters, film thickness and surface morphology have been considered. $\mathrm{SiN}_{x}$ films can exhibit a compressive or a tensile internal stress, ranging from -1970 to $+465 \mathrm{MPa}$, depending on deposition parameters. Among published results, usual reported residual stress for PECVD films is compressive. Versatility of our experimental ECR equipment allows one to deposit films exhibiting a weak stress in the range of a few tens MPa. On the basis of atomic force microscopy observations, a correlation between the intensity of the stress and the granular morphology of the films has been observed. The rms value for $\mathrm{SiN}_{x}$ film surfaces is never higher than $1.5 \mathrm{~nm}$, with a grain height ranging from 1.2 to $5 \mathrm{~nm}$ and a grain width varying from 20 to $60 \mathrm{~nm}$. Both the grain size and the residual stress vary with the thickness of the films. This work highlights the influence of the initial surface properties on the deposition mechanism. An exhaustive review of the stress generation model is given and a tentative interpretation for the origin of stress, either compressive or tensile, is proposed. () 2004 American Vacuum Society. [DOI: 10.1116/1.1776179]
\end{abstract}

\section{INTRODUCTION}

$\mathrm{Si}_{3} \mathrm{~N}_{4}$ dielectric films are widely used for microelectronics, optoelectronics and microelectromechanical system (MEMS) devices. This includes passivation, masks for lithography or ion implantation, optical coatings or waveguides and films for MEMS. Deposition techniques, involving low energy species, such as electron cyclotron resonance-plasma enhanced chemical vapor deposition

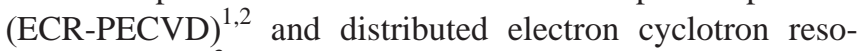
nance (DECR) ${ }^{3}$ techniques, have been developed recently to produce, at low temperature, high quality dielectric $\mathrm{SiN}_{x}$ films. It was found that, as for conventional rf PECVD techniques, the films generally exhibit a residual stress, which could be dependent, as mentioned earlier in the literature, ${ }^{4,5}$ on the deposition technique and parameters. Over the past years, a large amount of stress data has been reported for films prepared in various conditions. General trends emerge from the numerous publications dedicated to the subject. It appears that films deposited by techniques involving high energy and physical mechanisms, like reactive ion sputtering ${ }^{6,7}$ and high rf bias, ${ }^{8,9}$ lead to highly compressive strained films. PECVD techniques, involving low rf bias at relatively low temperature $\left(\leqslant 400^{\circ} \mathrm{C}\right)$, allow the stress to be

\footnotetext{
${ }^{a}$ Author to whom correspondence should be addressed. Present address: Laboratoire des Plasmas et des Couches Minces, Institut des Matériaux Jean Rouxel, UMR CNRS 6502, Université de Nantes, BP 32229, 44322 Nantes, Cedex 3, France; electronic mail: marie-paule.besland@cnrsimn.fr
}

reduced at lower compressive values. ${ }^{10}$ However, CVD deposition techniques, performed in a high temperature range (typically $650-850^{\circ} \mathrm{C}$ ), induce tensile strain in the films,${ }^{11}$ mainly correlated to high density. ${ }^{12}$ Works also report the possibility of obtaining both types of film, i.e., compressively or tensely strained films, with the same technique, by varying deposition parameters, like deposition pressure, ${ }^{13}$ gas phase composition, ${ }^{14,15}$ addition of an inert gas ${ }^{16}$ or bias variation. ${ }^{17}$ The use of a hydrogenated gas in the plasma can also favor the decrease of internal stress. ${ }^{18}$ Some workers have succeeded in defining experimental conditions for low stress film deposition. ${ }^{8,19,20}$

At the same time, a large number of studies have been dedicated to the understanding of this internal stress generation. ${ }^{21-23}$ Most publications have reported the participation of two contributions for the residual stress in thin films reported on a substrate, namely a thermal and an intrinsic contribution. To a large extent, the approach of Cammarata $^{24}$ appears as the most relevant. Indeed, the residual stress can be expressed by the sum of three contributions: (i) thermal stress due to differences in the thermal expansion coefficients of the film and substrate, (ii) epitaxial or coherency stress due to lattice matching between film and substrate, (iii) intrinsic stress which refers to the stress produced by a change of film density during or after deposition. When compared to crystalline film epitaxy, the amorphous film growth process like the plasma growth process is not well understood. A granular morphology in evaporated films can arise from limited surface diffusion and competition 
shadowing in a so-called "columnar" growth, ${ }^{25}$ early observed for sputter-deposited thin films. ${ }^{26}$ Nucleation can be favored when the surface free energy of a deposited film plus the free energy of the film-substrate interface is higher than the free energy of the substrate surface.

Even if the microscopic origin of intrinsic stress in the films is recurrently a matter of discussion, ${ }^{27-30}$ and despite an increasing technological interest, few reports are dedicated to the study of residual stress in ECR films. ${ }^{22,27,31}$

First of all, in order to achieve an actual stress reduction in $\mathrm{SiN}_{x}$ films deposited by ECR plasma on silicon substrates, we have studied a large range of process parameters: deposition temperature, ranging from room temperature to $300^{\circ} \mathrm{C}$, and deposition pressure in the $0.65-2.4 \mathrm{mTorr}$ range. As a result, we have specified experimental conditions to achieve such a stress reduction. As we did so, we have obtained some insights into the stress process itself by studying: (i) the stress distribution between substrate and film as the film thickness increases, (ii) the initial roughness of the substrate as an important factor for the film/substrate coherence, and (iii) the surface film morphology as a fingerprint of the intrinsic film texture.

\section{EXPERIMENT}

$\mathrm{SiN}_{x}$ film depositions were carried out in a plasma reactor, which is part of an ultrahigh vacuum $\mathrm{X}$-ray photoelectron spectroscopy (XPS) multi-chamber system, including an XPS surface analysis chamber. The plasma is produced by an Astex ECR S-250 compact source, with low microwave power $(2.45 \mathrm{GHz})$, tunable up to $250 \mathrm{~W}$. The precursor gases are $\mathrm{N}_{2}$, which is introduced in the plasma source and $\mathrm{SiH}_{4}$, which is injected through a dispersal ring. On the basis of previous optimization of the process, ${ }^{32}$ the deposition parameters were chosen as follows: microwave power $200 \mathrm{~W}$, electromagnetic coil supply current $22 \mathrm{~A}$, substrate to source distance $22 \mathrm{~cm}$.

Substrates used in. this work were $p$-type (100) oriented 2 in silicon wafers from ACM, whose thickness is in the $380 \mu \mathrm{m}$ range. Film thickness, ranging from 400 to $2000 \AA$, refractive index and homogeneity were checked in situ by ellipsometric measurements, performed at an incidence angle of $70.5^{\circ}$, with a commercial phase modulated ellipsometer (Jobin-Yvon UVISEL) mounted on the plasma chamber through viewports equipped with strain free fused quartz windows.

In situ ellipsometric measurements, calibrated to a pyrometer and the melting points of In and InSb, were used for a precise surface temperature control. The sample was heated using a manually controlled filament which permits heating up to $600^{\circ} \mathrm{C}$. To calibrate the variation of the ellipsometric parameters, $\Psi$ and $\Delta$, with the temperature, we added two pieces of indium and of InSb on the sample holder close to the substrate, which enabled use of the reference of the room temperature $\left(20^{\circ} \mathrm{C}\right)$ and the melting points of indium $\left(156^{\circ} \mathrm{C}\right)$ and $\operatorname{InSb}\left(525^{\circ} \mathrm{C}\right)$. Above $250^{\circ} \mathrm{C}$, a pyrometer was used to correlate ellipsometric measurements to temperature. Details on temperature calibration procedure have been pub- lished earlier by co-workers. ${ }^{33,34}$ This procedure allows a very accurate control of the surface temperature, at each step of the process.

The chemical composition of the films was determined both by in situ X-ray XPS surface analysis and ex situ nuclear reaction analysis. Atomic force microscopy (AFM) observations were performed ex situ to study the surface morphology of the films. Each series of films was observed with the same tip and lateral dimensions given after a reductive correction of $30 \%-40 \%$ to take into account the enlargement of grains size by the tip.

The etch rate is known to be very sensitive to the density of the film and to its hydrogen content. ${ }^{37-39}$ The etch rate was measured in a dilute solution (1:7) of commercial buffered oxide etchant $\left(\mathrm{NH}_{4} \mathrm{~F} / \mathrm{HF} / \mathrm{H}_{2} \mathrm{O}: 40 / 49 / 11\right)$ in de-ionized water. In the same conditions, a low pressure chemical vapor deposition (LPCVD) silicon nitride, used as a reference, was characterized by an average etch rate of $4 \AA \mathrm{min}^{-1}$. At least, the half thickness of the films was etched to check their homogeneity in depth.

We studied the variation of the mechanical properties of the films versus: (i) the film thickness; (ii) the substrate temperature [room temperature $(\mathrm{RT})$ to $300^{\circ} \mathrm{C}$ ]; and (iii) the total pressure, in the range of $0.65-2.4 \mathrm{~m}$ Torr, at fixed gas flow rate ratio $\mathrm{N}_{2} / \mathrm{SiH}_{4}=15$.

The stress in our films has been calculated by the bendbending method, where the radius of the bent, coated substrate is determined and used to calculate the residual stress. Recently Freund ${ }^{35}$ and co-workers extended the use of the simplified form of Stoney's formula ${ }^{36}$ to a broader class of film-substrate configurations. In our case, we can properly assume that geometrical requirements and mechanical assumptions $^{37}$ are verified: (i) the film and the substrate thickness are small compared to the lateral dimensions, (ii) the substrate thickness is much greater than the film thickness, (iii) the film thickness is uniform with good adhesion to the substrate, (iv) the stress is isotropic, without any preferential direction, i.e., the curvature of the substrate is uniform, (v) the deformation both for the film and the substrate is situated in the elastic domain. The internal stress in the deposited film is calculated from the change in the substrate curvature from $\tau_{0}=1 / R_{0}$ for the bare substrate to $\tau=1 / R$ after the thin film deposition, with the following formula:

$$
\sigma=\frac{E_{s} \cdot t_{s}^{2}}{6\left(1-\nu_{s}\right) \cdot t_{f}} \cdot\left(\frac{1}{R}-\frac{1}{R_{0}}\right),
$$

where $R_{0}$ is the radius of curvature of the bare Si substrate and $R$ is the radius of curvature after the deposition of the film on the substrate, $E_{s}$ and $\nu_{s}$ are, respectively, the Young's modulus and Poisson ratio of the substrate, and $t_{s}$ and $t_{f}$ are the thickness of the substrate and the film, respectively, equal to $380 \mu \mathrm{m}$ and in the $800-1000 \AA$ range. The value of $E_{s} /\left(1-\nu_{s}\right)$ for substrate $\mathrm{Si}(100)$ is $1.8 \times 10^{11} \mathrm{~Pa}$. The accuracy of the stress value varies in the $+/-30-80 \mathrm{MPa}$ range. The variation of substrate curvature has been checked by interferometry. The estimation is based on the analysis of Newton's rings which appear after reflection of a monochro- 
TABLE I. Deposition parameters and characteristics for $\operatorname{SiN}_{x}$ films of this study. For all films the other experimental parameters were as follows: Microwave power of $200 \mathrm{~W}$, electromagnetic coil current supply $22 \mathrm{~A}$, source to substrate distance of $22 \mathrm{~cm}$, gas flow rate ratio $\mathrm{N}_{2} / \mathrm{SiH}_{4}=15$.* The hydrogen content is given in $\%$ of atoms $/ \mathrm{cm}^{2}$.

\begin{tabular}{|c|c|c|c|c|c|c|c|c|c|c|c|c|}
\hline Sample & $\begin{array}{l}\text { Radius } \\
R_{0}(\mathrm{~m})\end{array}$ & $\begin{array}{l}\text { Radius } \\
R_{1}(\mathrm{~m})\end{array}$ & $T_{S}\left({ }^{\circ} \mathrm{C}\right)$ & $\begin{array}{c}\text { Pressure } \\
\text { (mTorr) }\end{array}$ & $\begin{array}{c}\text { Thickness } \\
(\AA)\end{array}$ & $\begin{array}{c}\text { Deposition } \\
\text { rate } \\
(\AA / \mathrm{min})\end{array}$ & $\begin{array}{l}\text { Optical } \\
\text { index } \\
\text { at } 3 \mathrm{eV}\end{array}$ & $\begin{array}{l}\text { N/Si ratio } \\
\quad \text { (XPS) }\end{array}$ & $\begin{array}{c}\% \mathrm{H} \\
\text { content* }\end{array}$ & $\begin{array}{l}\text { Density } \\
\mathrm{g} \mathrm{cm}^{-3}\end{array}$ & $\begin{array}{l}\text { Etch rate } \\
(\AA / \mathrm{min})^{\mathrm{a}}\end{array}$ & $\begin{array}{c}\text { Stress } \\
(\mathrm{MPa})^{\mathrm{b}}\end{array}$ \\
\hline S120 & & & $\mathrm{RT}$ & 1.2 & 800 & 13 & 1.96 & 1.45 & 14 & 2.77 & 300 & -554 \\
\hline $\mathrm{S} 122$ & & & 200 & 1.2 & 810 & 9 & 2.02 & 1.4 & 9 & 2.87 & 80 & -452 \\
\hline S124 & & & 300 & 1.2 & 750 & 8 & 2.06 & 1.33 & 6 & 3.04 & 10 & -704 \\
\hline S170 & $\sim 0$ & -96 & 200 & 1.2 & 430 & 9.6 & 2 & $\cdots$ & $\cdots$ & $\cdots$ & $\cdots$ & 625 \\
\hline S160 & -139 & -39 & 200 & 1.2 & 820 & 9.5 & 2 & 1.33 & $\ldots$ & $\cdots$ & 85 & -600 \\
\hline S165 & -127.5 & -45.6 & 200 & 1.2 & 795 & 9 & 2 & 1.4 & $\ldots$ & $\ldots$ & 90 & -480 \\
\hline S171 & 358 & -46.8 & 200 & 1.2 & 1500 & 10 & 1.99 & $\ldots$ & $\ldots$ & $\ldots$ & $\ldots$ & -446 \\
\hline S172 & 1075 & -29 & 200 & 1.2 & 2090 & 10 & 2 & $\ldots$ & $\ldots$ & $\ldots$ & $\ldots$ & -460 \\
\hline S174 & & & 200 & 0.65 & 740 & 9 & 2 & 1.51 & 10 & 2.83 & 380 & -1970 \\
\hline S175 & & & 200 & 1.75 & 720 & 7 & 1.96 & 1.4 & $\ldots$ & $\ldots$ & 150 & +356 \\
\hline S163 & -139 & 182 & 200 & 2 & 830 & 7 & 1.95 & $\ldots$ & $\cdots$ & $\ldots$ & $\cdots$ & +410 \\
\hline S164 & -336 & 248 & 200 & 2.33 & 870 & 7 & 1.96 & 1.41 & 8 & 2.85 & 520 & +220 \\
\hline S127 & & & 200 & 2.4 & 890 & 7.5 & 1.95 & $\ldots$ & 9 & $\ldots$ & $\ldots$ & +465 \\
\hline
\end{tabular}

${ }^{\mathrm{a} E t c h i n g ~ s o l u t i o n: ~ B O E: ~} \mathrm{H}_{2} \mathrm{O}=1: 7$.

${ }^{\mathrm{b}}$ Convention: $+=$ concave and $-=$ convex.

matic light (namely $\lambda=535 \mathrm{~nm}$ of a thallium lamp) on the substrate through an optically flat quartz window. ${ }^{7}$

\section{RESULTS}

\section{A. Internal stress measurements}

Our measurements were analyzed through a raw application of Stoney's formula using the data curvature changes presented in Table I.

In standard deposition conditions, i.e., $P_{w}=200 \mathrm{~W}, I_{B}$ $=22 \mathrm{~A}, D=22 \mathrm{~cm}, T_{\mathrm{sub}}=200^{\circ} \mathrm{C}$, and total pressure of 1.2 mTorr, the $800 \AA$ ECR $\operatorname{SiN}_{x}$ films exhibit a compressive internal stress in the range of -580 to $-450 \mathrm{MPa}$, giving a mean value of $-520+/-60 \mathrm{MPa}$. This observation is the most common behavior for dielectric films deposited by plasma enhanced techniques. ${ }^{4,9,31,38}$ We measured the evolution of the internal stress for films deposited in standard conditions, i.e., $1.2 \mathrm{mTorr}$ and $200^{\circ} \mathrm{C}$, with increasing thickness, in the 400-2000 ̊ range (Fig. 1). As the thickness increases, the total stress first decreases and secondly saturates for a thickness of $1200 \AA$. Thinner $\operatorname{SiN}_{x}$ films exhibit a higher compressive stress than the thicker films. The same
800- $\AA$-thick $\operatorname{SiN}_{x}$ film has been deposited on two silicon substrates, with significant difference in initial roughness (rms of 0.1 and $1.5 \mathrm{~nm}$ ). The stress values after deposition were, respectively, -580 and $-310 \mathrm{MPa}$. This observation clearly highlights the influence of the substrate morphology on the internal structure of the film.

The effect of the total pressure on the internal stress was investigated for 1000 - $\AA$ thick $\operatorname{SiN}_{x}$ films. The variation is shown in Fig. 2: as the pressure increases from 0.65 to 2.4 mTorr, the total internal stress varies from a highly compressive $(-1970 \mathrm{MPa})$ to a moderate tensile value (+465 MPa).

The effect of the deposition temperature on the internal stress is shown in Fig. 3. In standard deposition conditions, $\mathrm{SiN}_{x}$ films, obtained with nonintentional heating of the sample, exhibit a compressive strain of $-550 \mathrm{MPa}$ and $-310 \mathrm{MPa}$, respectively, for samples S161 and S162. An increase of the deposition temperature to $200^{\circ} \mathrm{C}$ promotes a slight variation of the internal stress. A further increase up to $300^{\circ} \mathrm{C}$ leads to a higher compressively strained film, at $-704 \mathrm{MPa}$.

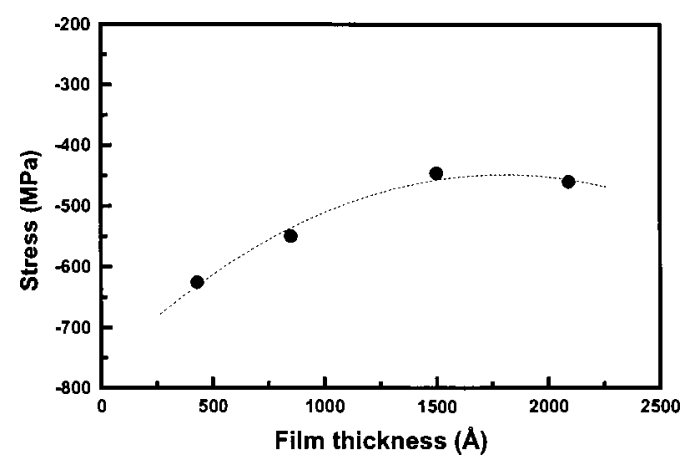

FIG. 1. Variation of the stress vs the thickness of the $\mathrm{SiN}_{x}$ films.

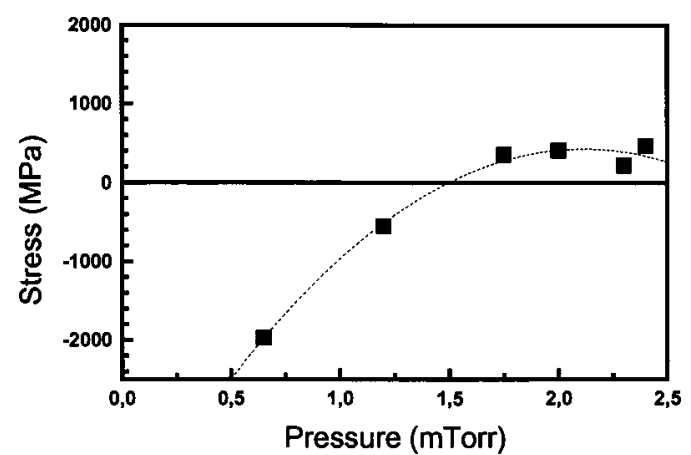

FIG. 2. Effect of the total pressure on the internal stress in the $\mathrm{SiN}_{x}$ films. 


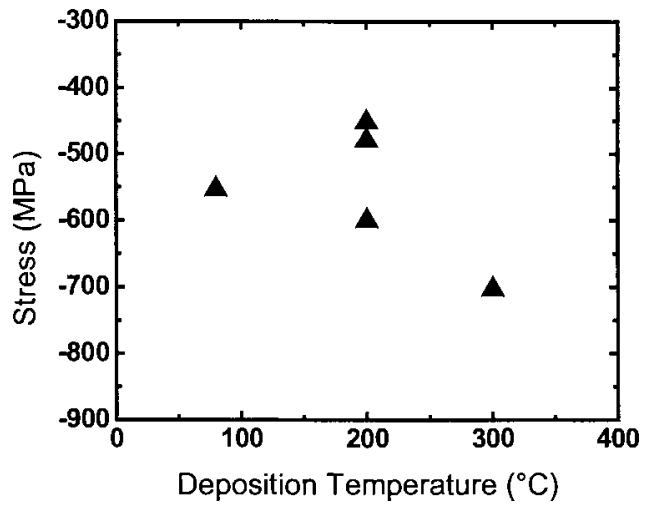

FIG. 3. Variation of the internal stress in $\operatorname{SiN}_{x}$ films vs the deposition temperature.

The thermal stress contribution $\sigma_{\text {th }}$ to the internal stress results from the difference in the thermal expansion of the film and the substrate between the deposition temperature $T_{d}$ and the measurement temperature $T_{m}$, which is RT in that study. $\sigma_{\text {th }}$ can be easily estimated using the following formula:

$$
\sigma_{\text {th }}=\frac{E_{f}}{\left(1-\nu_{f}\right)} \cdot\left(\alpha_{f}-\alpha_{s}\right)\left(T_{d}-T_{m}\right),
$$

where $\alpha_{f}$ and $\alpha_{s}$ are the thermal expansion coefficients for, respectively, the film and the substrate, and equal to 1.55 $\times 10^{-6}$ and $3.2 \times 10^{-6 \circ} \mathrm{C}^{-1}$, respectively. As the Young's modulus value for the film, the one given for LPCVD $\mathrm{SiN}_{x}$ film ${ }^{36}$ has been taken: $E_{f} / 1-\nu_{f}=3.7 \times 10^{11} \mathrm{~Pa}$. Thus, in our experimental conditions and for a deposition temperature ranging from $\mathrm{RT}$ to $300^{\circ} \mathrm{C}$, the thermal contribution to the internal stress is -30 and $-110 \mathrm{MPa}$, respectively, and these values are certainly overestimated ones.

In the bottom part of Table II, stress measurements are given for three $\mathrm{SiN}_{x}$ films, with thicknesses in the 700-800 ̊ range. They were deposited in standard condi- tions of temperature $\left(200^{\circ} \mathrm{C}\right)$, microwave power and coil supply, (200 W and $22 \mathrm{~A}$, respectively), for a total pressure of 1.75 mTorr and a flow rate ratio $\mathrm{N}_{2} / \mathrm{SiH}_{4}=15$. The differences between these samples stand in the way of pressure regulation.

For sample S175, the increase of pressure, from the standard pressure (1.2 mTorr) to 1.75 mTorr, was obtained by increasing the flow rate of both nitrogen and silane, from $18.75 / 1.25$ up to $30 / 2$, keeping the total flow rate ratio constant at 15. The film exhibits a tensile residual stress of +356 MPa. In the case of S177, the initial gas inlet is the same as for standard deposition at $1.2 \mathrm{mTorr}$ (Sample S160-S162-S165), but the pumping speed was decreased by closing the pumping valve, resulting in an increase of the deposition pressure up to 1.75 mTorr. The measured stress is very close to no stress $(+35 \mathrm{MPa})$. In the case of sample S176, the deposition pressure was increased to 1.75 mTorr by adding $9 \mathrm{sccm}$ of hydrogen in the gas plasma, resulting in an inlet quantity of nitrogen species equivalent to that of sample S177. The residual stress is compressive at $-200 \mathrm{MPa}$.

The last sample described in Table II (S166) was deposited in standard conditions, except for the coil supply, which was fixed at a lower value of $18 \mathrm{~A}$. The residual stress is once again modified to lower compressive stress, with a value of $-300 \mathrm{MPa}$. The results presented in Table II will be further discussed.

\section{B. AFM observations}

AFM observations of 1000- $\AA$-thick films deposited at RT and $200^{\circ} \mathrm{C}$ show, in both cases, a granular morphology (Fig. 4) with an average surface roughness of 1.1 and $1.4 \mathrm{~nm}$ and a grain lateral dimension of 50 and $20 \mathrm{~nm}$, respectively.

Figure 5 shows the surface morphology of $\mathrm{SiN}_{x}$ films deposited at increasing pressure. It is clearly observed that the grain size is also dependent on the deposition pressure: at low deposition pressure (0.65 $\mathrm{mTorr}), \mathrm{SiN}_{x}$ films exhibit

TABLE II. Variation of experimental parameters around the standard conditions of deposition and effects on some properties of the $\mathrm{SiN}_{x}$ films.

\begin{tabular}{lccccccccc}
\hline \hline Sample $^{\mathrm{a}}$ & $\begin{array}{c}\text { Radius } \\
R_{0}(\mathrm{~m})\end{array}$ & $\begin{array}{c}\text { Radius } \\
R_{1}(\mathrm{~m})\end{array}$ & $\begin{array}{c}\text { Pressure } \\
(\mathrm{mT} T \mathrm{r})\end{array}$ & $\begin{array}{c}\text { Thickness } \\
(\AA)\end{array}$ & $\begin{array}{c}V d \\
(\AA / \mathrm{min})\end{array}$ & $\begin{array}{c}\text { Optical index } \\
\text { at } 3 \mathrm{eV}\end{array}$ & $\begin{array}{c}\text { N/SI ratio } \\
(\mathrm{XPS})\end{array}$ & $\begin{array}{c}\text { Etch rate } \\
(\AA / \mathrm{min})\end{array}$ & $\begin{array}{c}\text { Stress } \\
(\mathrm{MPa})\end{array}$ \\
\hline $\mathrm{S} 161$ & -225.6 & -66.4 & 1.2 & 935 & 11 & 1.89 & $/$ & $/$ & -310 \\
$\mathrm{~S} 162$ & -196 & -47 & 1.2 & 790 & 9 & 1.98 & $\ldots$ & $\ldots$ & -550 \\
$\mathrm{~S} 166^{\mathrm{b}}$ & 169 & -393 & 1.2 & 795 & 6.5 & 1.9 & 1.49 & $/$ & -300 \\
$\mathrm{~S}_{175}{ }^{\mathrm{c}}$ & & & 1.75 & 720 & 7 & 1.96 & 1.4 & 150 & +356 \\
$\mathrm{~S}_{176}{ }^{\mathrm{d}}$ & & & 1.75 & 775 & 9 & 1.85 & 1.4 & 960 & -200 \\
$\mathrm{~S}_{177^{\mathrm{e}}}$ & & & 1.75 & 780 & 11 & 1.96 & 1.33 & 195 & +35 \\
\hline \hline
\end{tabular}

${ }^{\mathrm{a}}$ Without specifications, the experimental parameters were as follows: Microwave power $200 \mathrm{~W}$, coil current supply $\left(I_{b}\right) 22 \mathrm{~A}$, substrate temperature $200^{\circ} \mathrm{C}$, source-substrate distance $22 \mathrm{~cm}$, flow rate ratio $\mathrm{N}_{2} / \mathrm{SiH}_{4}$ $=18.75 / 1.25$.

${ }^{\mathrm{b}} \mathrm{S} 166$, the electromagnetic coil current supply was lowered to $18 \mathrm{~A}$.

${ }^{\mathrm{c}} \mathrm{S} 175$, higher flow rate ratio $\mathrm{N}_{2} / \mathrm{SiH}_{4}=30 / 2$.

${ }^{\mathrm{d}} \mathrm{S} 176$, increase of the total pressure by addition of $9 \mathrm{sccm} \mathrm{H}_{2}$.

${ }^{\mathrm{e}} \mathrm{S} 177$, standing gas inlet $\mathrm{N}_{2} / \mathrm{SiH}_{4}=18.75 / 1.25$; the higher pressure was obtained by lowering the pumping speed.

${ }^{\mathrm{f}}$ Etching solution: $\mathrm{BOE}: \mathrm{H}_{2} \mathrm{O}=1: 7$. 

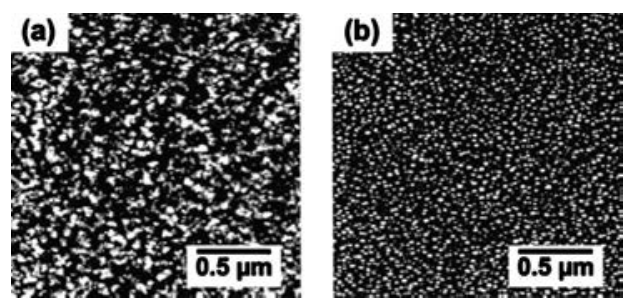

FIG. 4. AFM images of the $\operatorname{SiN}_{x}$ film surfaces for (a) room temperature deposition and (b) deposition temperature of $200^{\circ} \mathrm{C}$.

small grain size and roughness, $0.8 \mathrm{~nm}$ (height) and $0.2 \mathrm{~nm}$, respectively. For standard pressure of deposition (1.2 mTorr), both rms and grain height increase, respectively, to 1.5 and $1 \mathrm{~nm}$. For high deposition pressure (2.4 mTorr), the films are made up of larger grains with a height of $5 \mathrm{~nm}$, while the rms remains constant at $1.5 \mathrm{~nm}$.

The typical grain size and roughness of $\mathrm{SiN}_{x}$ films, deduced from AFM observations, are gathered in Table III. It appears that at low pressure, a smooth initial surface and high deposition temperature lead to high compressive stress, correlated to a small grain size (S174). An increase of surface roughness or deposition pressure and a decrease of
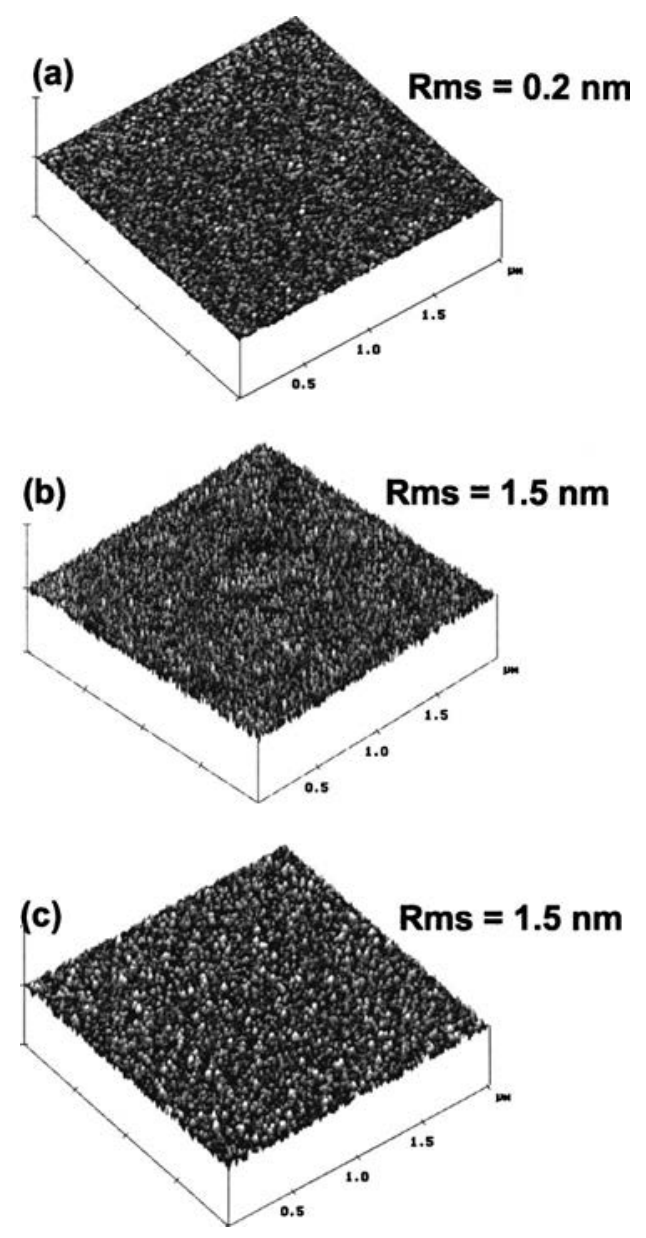

FIG. 5. Typical top-view AFM images of surface morphology vs the deposition pressure: (a) low pressure $0.65 \mathrm{mTorr}$, (b) standard pressure 1.2 mTorr, and (c) high pressure 2.3 mTorr.
TABLE III. Grain size, roughness (deduced from AFM observations) wet etch rate and residual stress of $\mathrm{SiN}_{x}$ film.

\begin{tabular}{lcccccc}
\hline \hline & $\begin{array}{c}\text { Thickness } \\
(\AA)\end{array}$ & $\begin{array}{c}\text { Grain } \\
\text { height } \\
(\mathrm{nm})\end{array}$ & $\begin{array}{c}\text { Grain } \\
\text { width } \\
(\mathrm{nm})\end{array}$ & $\begin{array}{c}\mathrm{rms} \\
(\mathrm{nm})\end{array}$ & $\begin{array}{c}\text { Etch rate } \\
(\AA / \mathrm{min})\end{array}$ & $\begin{array}{c}\text { Stress } \\
(\mathrm{MPa})\end{array}$ \\
\hline Sample $^{\mathrm{a}}$ & 800 & 1 & 50 & 1.1 & 300 & -554 \\
$\mathrm{~S} 120$ & 740 & 0.8 & 20 & 0.2 & 380 & -1970 \\
S174 & 795 & 1 & 20 & 1.5 & 90 & -480 \\
S165 & 890 & 5 & 60 & 1.5 & 500 & +465 \\
S127 & & &
\end{tabular}

${ }^{\mathrm{a}}$ Experimental deposition parameters are given in Table I.

deposition temperature produce a decrease of the internal stress, associated with an increase of the grain size (S162,S165,S120). Finally, for deposition pressure over 1.5 mTorr, the films are slightly tensely strained and made up of larger grains (S127). For the highest pressure studied, the highest grain size was observed with the same rms of $1.5 \mathrm{~nm}$.

The evolution of the granular morphology during the first stages of deposition was controlled by AFM observations. Typical values are given in Table IV. A granular morphology is observed even for very thin films of $30 \AA$ (sample S190) produced by direct nitridation of silicon [Fig. $6(\mathrm{a})]$. The observed rms of $0.1 \mathrm{~nm}$ is similar to that of a bare silicon substrate, observed after removal of the native oxide by a HF dip. For a $180-\AA$-thick $\operatorname{SiN}_{x}$ film (sample S191), deposited on $\mathrm{Si}$ in standard conditions at $200^{\circ} \mathrm{C}$ [Fig. 6(b)], the rms increases to $0.3 \mathrm{~nm}$, and the grain height grows up from 0.2 to $1 \mathrm{~nm}$, while a similar width of grain of $23-25 \mathrm{~nm}$ is observed at the two stages.

As a first observation, these results show a correlation between the intensity of the stress and the granular morphology of the films: as the compressive strain increases, the grain size decreases. It appears that larger strains are observed for smoother surfaces and thinner films.

\section{DISCUSSION}

As mentioned in the Introduction, among the various published models for residual stress generation in thin deposited films, the Cammarata's approach ${ }^{24,39}$ appears the most relevant to the results of this study. The residual stress is considered as the sum of three contributions: (i) thermal stress due to differences in the thermal expansion coefficients of

TABLE IV. Grain size and roughness of silicon surfaces and first stages of $\mathrm{SiN}_{x}$ deposition, as deduced from AFM observations.

\begin{tabular}{lcccc}
\hline \hline Sample & rms (nm) & $\begin{array}{c}\text { Grain } \\
\text { height (nm) }\end{array}$ & $\begin{array}{c}\text { Grain } \\
\text { width (nm) }\end{array}$ & $\begin{array}{c}\text { Film } \\
\text { Thickness }(\AA)\end{array}$ \\
\hline${\mathrm{S} 161^{\mathrm{a}}}^{\mathrm{b}}$ & 0.1 & 0.1 & 20 & No film \\
${\mathrm{S} 162^{\mathrm{b}}}_{\mathrm{S} 190^{\mathrm{b}}}$ & 1.5 & $2-4$ & $30-40$ & No film \\
${\mathrm{S} 191^{\mathrm{c}}}^{\mathrm{c}}$ & 0.1 & 0.2 & 23 & 30 \\
\hline \hline
\end{tabular}

${ }^{\mathrm{a}}$ Experimental deposition parameters are given in Table II.

${ }^{\mathrm{b}}$ Sample obtained by direct nitridation of a Si substrate.

${ }^{\mathrm{c}}$ Deposited in standard experimental condition of sample S160. 

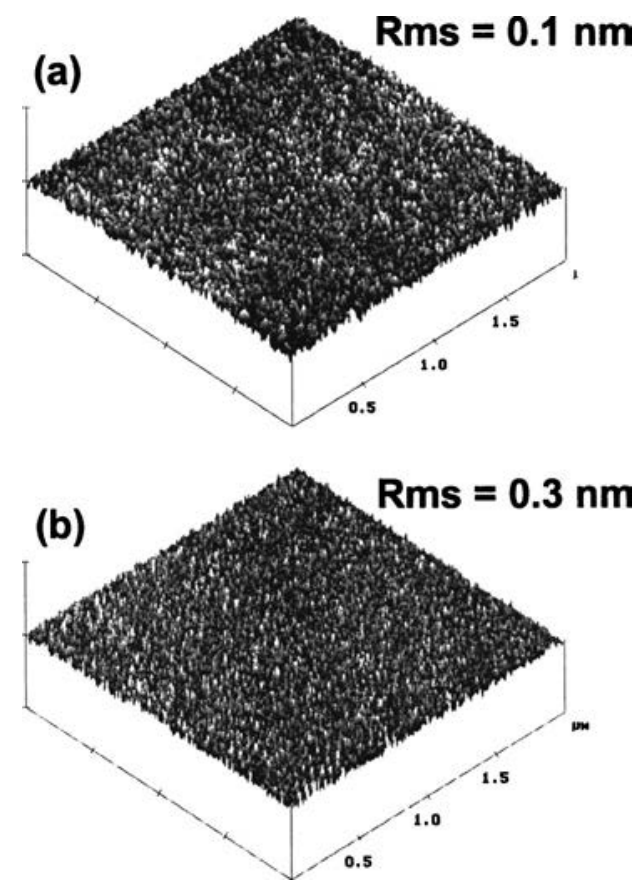

FIG. 6. Top-view AFM images $(2 \times 2 \mathrm{~mm})$ of the first stages of $\operatorname{SiN}_{x}$ film deposition on silicon substrate (a) $30 \AA \mathrm{SiN}_{x}$ (nitrided $\mathrm{Si}$ ) and (b) thin $180 \AA \mathrm{SiN}_{x}$ film.

the film and substrate, (ii) epitaxial stress due to lattice matching between film and substrate, (iii) intrinsic stress which refers to the stress produce by a change of film density during or after deposition.

As the thermal stress contribution, in our experimental conditions, is never higher than $100 \mathrm{MPa}$ (as estimated in the previous section), other phenomena must be involved to explain our observations. Our results show that the $\mathrm{Si}_{3} \mathrm{~N}_{4}$ films have a granular morphology even for very thin films, produced by direct nitridation of silicon (sample S190). Compressive stress is observed in most cases. Figure 1shows that the highest strains are found for the thinnest films. We think that this behavior can be attributed to a planar epitaxial strain associated with a molar volume change in the silicon network at the $\mathrm{Si} / \mathrm{Si}_{3} \mathrm{~N}_{4}$ interface. ${ }^{40}$

As the $\mathrm{Si}_{3} \mathrm{~N}_{4}$ film is highly compressively strained near the interface, stress relaxation can produce three-dimensional (3D)-island nucleation in addition to surface diffusion. ${ }^{41}$ Increasing the thickness of the nitride layer leads to a decrease of the strain associated with some partial relaxation favored by the flexibility of the $\mathrm{Si}_{3} \mathrm{~N}_{4}$ amorphous network and the 3D morphology. For thicknesses above $1500 \AA$, the stress is observed to stabilize (Fig. 1). A saturation at the same value has been reported by French and co-workers ${ }^{20}$ for LPCVD $\mathrm{SiN}_{x}$ films. This epitaxial strain interpretation is also supported by the fact that rough silicon surfaces lead to lower stressed films rather than smooth surfaces: stress is dependent on the substrate's nature (samples S161, S162).

The results shown in Fig. 2 indicate that intrinsic stress may play a major role in some conditions, since a $\mathrm{SiN}_{x}$ film may exhibit a compressive stress, a tensile stress or no stress depending only on the pressure in the reactor. Various models ${ }^{7,12,21-23}$ have been involved in the literature to explain the origin of tensile and compressive intrinsic stress. A strong correlation exists between this intrinsic stress, the hydrogen content ${ }^{11}$ and the density of the films. ${ }^{18,42}$

Silicon nitride films can be deposited either using ammonia $\mathrm{NH}_{3}$ or nitrogen $\mathrm{N}_{2}$ as a precursor. When ammonia is used, $\mathrm{SiN}_{x}$ films exhibit mainly a weak tensile residual stress. ${ }^{18,43}$ In this study, considering the physico-chemical characteristics given in Tables I and II, no simple and evident correlation can be highlighted. Since low density, i.e., high etch rate, was observed either for compressive residual stress (samples S174 and S176) or tensile residual stress (samples S164, S175, S177). Likewise, the transition from compressive to tensile residual stress is not correlated either, for our samples, to the chemical composition and the Si concentration in the film, ${ }^{14,22}$ since we never obtained $\mathrm{N} / \mathrm{Si}$ ratios lower than the stoichiometric value 1.33 , i.e., Si-rich films. ${ }^{32}$ Taylor $^{10}$ has shown, through Fourier transform infrared (FTIR) analysis of PECVD $\mathrm{SiN}_{x}$ thin films, a correlation between the intensity of intrinsic compressive stress and the ratio between $\mathrm{N}-\mathrm{H}$ and $\mathrm{Si}-\mathrm{H}$ bonds: $\mathrm{N}-\mathrm{H}$ rich films exhibited highly compressive stress. In that study, the correlation of the stress with the hydrogen content is observed only when the deposition temperature is varied (Fig. 3). Higher residual stress is observed for a higher deposition temperature (samples S120-122-124 in Table I) where the hydrogen concentration is lower (see also Ref. 32). Denser films exhibit low hydrogen content and higher compressive stress.

Some models involve material modification during deposition or structural evolution due to aging with atmospheric moisture. ${ }^{44,45}$ The general behavior is a considerable increase in compressive stress, promoted by structural changes in the network by $\mathrm{Si}-\mathrm{O}-\mathrm{Si}$ bridge formation. Such relaxation of stress has also been observed in the case of fluorinated $\mathrm{Si}-\mathrm{O}-\mathrm{F}$ thin films. ${ }^{27}$ The evolution of residual stress in our films under aging was not investigated. Nevertheless, this model cannot be invoked to explain the evolution towards tensile residual stress.

In a few words, the various correlations reported in the literature for PECVD thin films are in agreement with our observations for the low pressure range, i.e., lower than 1.2 mTorr. However, the transition to tensile strained films at higher pressure cannot be explained by the previously discussed mechanism.

Nevertheless, this is a well known behavior for thin films deposited by sputtering techniques. ${ }^{26,46}$ Typically at low pressure, ion bombardment plays an important part in the deposition mechanism, leading to a tightly packed columnar structure. The deposited films are compressively stressed, due to a great forward sputtering. At higher pressure, however, because of a shorter mean free path and a high number of collisions, the energy of ionic species impinging the surface is weak, promoting a more porous columnar structure. Tensile stress is generated through attractive inter-atomic forces between columns in the porous structure. Thus, while the working pressure increases, a typical compressive-to- 


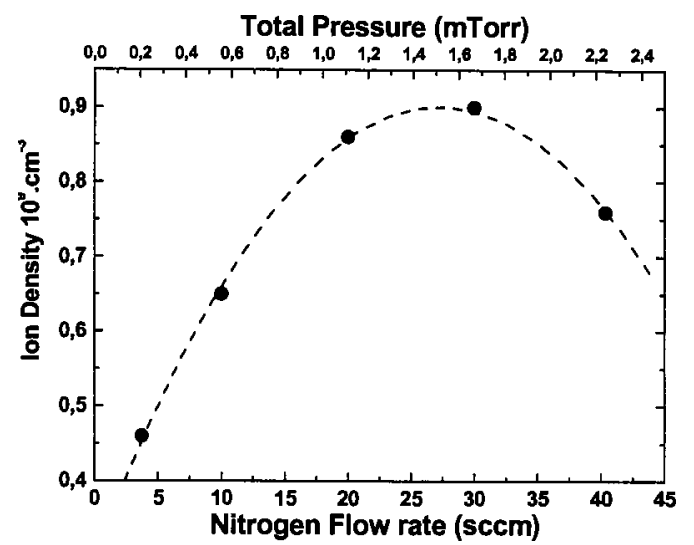

FIG. 7. Variation of ion density vs nitrogen flow rate and total pressure for standard plasma parameters (microwave power $200 \mathrm{~W}$, coil current supply $22 \mathrm{~A})$ measured at sample location, i.e., $22 \mathrm{~cm}$ from the source exit.

tensile transition is observed for sputtered films. Intrinsic tensile stresses are created through coalescence of neighboring islands. Similar models for the generation of tensile stress in amorphous thin films have been considered only very recently by researchers. ${ }^{47,48}$

Thus, to understand this particular behavior of our ECR films, two characteristics have to be considered: on the one hand, the ion density versus the deposition pressure (Fig. 7) and, on the other hand, the ion energy (Table V). At low pressure, the ion density is the lowest $\left(0.7 \times 10^{9} \mathrm{~cm}^{-3}\right)$ and the ion energy is the highest $(32 \mathrm{eV})$. As a result, the ion bombardment is strong and tends to induce strong compressive stresses in the films. Actually, we measured a high compressive stress of $-1970 \mathrm{MPa}$. As the pressure increases to 1.2 mTorr, the ion density reaches the highest values range, around $0.9 \times 10^{9} \mathrm{~cm}^{-3}$. Meanwhile the ion energy decreases to $24 \mathrm{eV}$, as a consequence of the higher probability of ion collisions. This leads to a decrease of the ion bombardment effect and the generation of a lower compressive stress in the $\operatorname{SiN}_{x}$ films $(-500 \mathrm{MPa})$, in agreement with the literature. ${ }^{8,9}$ The further variation of the internal stress with a further increase of the deposition pressure up to 2.3 mTorr is less expected. At high pressure, the ion energy still decreases to $16 \mathrm{eV}$, whereas the ion density shows a significant decrease down to $0.75 \times 10^{9} \mathrm{~cm}^{-3}$. Therefore, the compressive effect due to ion bombardment continues to decrease. Nevertheless,

TABLE V. Plasma parameters as calculated from Langmuir probe measurements (in Ph.D. thesis M. Lapeyrade- Lyon ECL, 1999). $V$ po =potential at source exit aperture; $\Delta V p=$ potential difference between source exit aperture and sample location; $V f=$ floating potential at sample location; $V p-V f$ $=$ Difference between plasma potential and floating potential at sample location; and $(22 \mathrm{~cm})$.

\begin{tabular}{lccccc}
\hline \hline $\begin{array}{l}\text { Pressure } \\
(\mathrm{mT} \text { Torr })\end{array}$ & $V p o(\mathrm{~V})$ & $\Delta V p(\mathrm{~V})$ & $V_{p}-V_{f}$ & $\begin{array}{c}\text { Ion energy } \\
(\mathrm{eV})\end{array}$ & $\begin{array}{c}\text { Electron } \\
\text { temperature } \\
(\mathrm{eV})\end{array}$ \\
\hline 0.6 & 40 & 18 & 14 & 32 & 6.5 \\
1.2 & 25 & 16.2 & 8 & 24 & 3 \\
2.3 & 15 & 12.8 & 3.5 & 16 & 2.5 \\
\hline \hline
\end{tabular}

the origin of the tensile stress measured in such a pressure range cannot be easily understood on the basis of the ion density decrease alone.

To a large extent, the way of varying the deposition pressure in our equipment should be taken into account. Indeed, our plasma chamber is not equipped with a variable pumping speed valve. Thus, the total pressure is directly dependent on the gas flow inlet. This means that, at higher pressure, the amount of species introduced in the chamber is higher. Nevertheless, the ion density measured at the sample location is lower and, in addition, the ion energy is lower, too. We can thus conclude that the concentration of unionized species is higher, with no contribution in the ionic bombardment.

This is indeed supported by the results obtained with samples S175 and S177, deposited at the same total pressure of 1.75 mTorr but with different gas inlets (Table II). In the case of S175, the variation of pressure is obtained by increasing both the nitrogen and silane inlet flow. As expected and in agreement with our previous arguments, we measured a tensile residual stress of $+356 \mathrm{MPa}$.

In the case of sample S177, elaborated at low pumping speed, a longer residence time in the chamber should be expected for all species, allowing them to promote more collisions. The first consequence should be a greater loss of energy for charged species, resulting in an important decrease of ion bombardment, i.e., lowering the compressive stress generation. The measured residual stress is close to zero $(+35 \mathrm{MPa})$; this is the lowest observed stress in this study.

As pointed out by Noskov et al., ${ }^{12}$ stress at the free growing surface of the film is close to zero. Chemical reactions occurring at the surface itself will not result in additional stress in the film. Whereas reactions occurring at the subsurface can promote relaxation phenomena and generate stress. Reactions involving loss of hydrogen could favor the appearance of tensile stress in the films. In many respects, the loss of hydrogen and the related stress are correlated through a complex balance, involving the amount of hydrogen in the films, the ratio between $\mathrm{Si}-\mathrm{H}$ and $\mathrm{Si}-\mathrm{NH}$ bonds, the deposition rate, the ion bombardment and the substrate temperature. Our results do not allow to conclude fully on this balance.

Nevertheless, the following hypothesis can be drawn from the above observations: the deposition mechanism should be the result of a competition between, on the one hand, a physical process controlled by ion bombardment and, on the other hand, a chemical process controlled by chemical reactions taking place during deposition. The former is known to favor the generation of a compressive stress in the deposited film. ${ }^{6-9}$ For the later, tensile stress ${ }^{27,28}$ is mainly generated.

These two opposite behaviors have been pointed out recently by Yota ${ }^{49}$ in a comparative study of the properties of silicon nitride films deposited by three different plasma techniques: inductively-coupled plasma high-density plasma chemical vapor deposition (HDP CVD), plasma enhanced chemical vapor deposition (PECVD), and low pressure chemical vapor deposition (LPCVD). The authors show that 
the two former films exhibit moderate compressive stress, -1500 and $-3800 \mathrm{MPa}$, respectively, whereas the latter is highly tensile in the GPa range.

The stress variation shown in Fig. 2 can therefore be explained as follows: in the low pressure range, below 1 mTorr, the ion bombardment is strong and controlled the deposition, leading to a highly compressive stress generation; whereas in the high pressure range, above 1.7 mTorr, the ion bombardment is limited and grain growth can thus occur to a large extent. The density of $\mathrm{SiN}_{x}$ films deposited at high pressure is low (Table I), and has been confirmed by the high etch rates obtained for samples S164, S175, S176, and S177. Table I shows the good correlation between etch rate, hydrogen concentration and density of the films: denser films exhibit a low hydrogen content, going along with a low etch rate.

As a last issue in this discussion, we can consider the correlation between the absolute value of the stress and the grain size, i.e., the height and width values. We highlight the relation of internal residual stress to grain size and etch rate. Lower etch rate and grain size are obtained for films deposited at 200 or $300^{\circ} \mathrm{C}$, for a pressure of $1.2 \mathrm{mTorr}, 80$ and $10 \AA \min ^{-1}$ respectively, compared to $4 \AA \mathrm{min}^{-1}$ for a standard LPCVD $\mathrm{Si}_{3} \mathrm{~N}_{4}$.

It is noticeable that high stress intensity of $-1990 \mathrm{MPa}$ is associated with low grain size $(0.8$ and $20 \mathrm{~nm}$, respectively, for height and width) and low roughness (rms of $0.2 \mathrm{~nm}$ ), whereas low stress amplitude of $+/-500 \mathrm{MPa}$ is associated with the same rms of $1.5 \mathrm{~nm}$, both for compressive or tensile stress. The difference between the two is a larger grain size (height and width) for tensely strained films than for compressively strained ones: 4.7 and $60 \mathrm{~nm}$ for the former and 1 and $40 \mathrm{~nm}$ for the latter. This increase of the grain size, in the high pressure range, appears to support a deposition mechanism governed mostly by chemical reactions than ion bombardment, which leads to a grain size increase, going along with the appearance of tensile strain in the films.

Obviously, a complete understanding of the deposition mechanism and aging studies would be needed to fully further understand the phenomena really involved in $\mathrm{Si}_{3} \mathrm{~N}_{4}$ films deposited by ECR plasma with our equipment. A varying valve pressure would allow the completion of the study of the pressure effect. In situ optical measurement of the internal stress during the film deposition, as described in the literature, ${ }^{35,50}$ would be of great interest to have some insight into the appearance of tensile stress.

\section{CONCLUSION}

In this work, the evolution of residual stress in $\mathrm{SiN}_{x}$ films deposited by ECR plasma has been considered versus some deposition parameters (deposition temperature, total pressure) and film thickness. In standard deposition conditions, ${ }^{32}$ silicon nitride films exhibit a compressive residual stress at $-500 \mathrm{MPa}$, as the average value, which is the lowest value reported in the literature for films deposited by the ECR plasma technique. AFM observations have shown a granular morphology, with a grain size strongly correlated to the re- sidual stress intensity. A transition from a compressively strained film to a tensile strained one has been clearly related to the deposition pressure. This transition, occurring in the 1.2-1.4 mTorr range, is rarely observed in PECVD deposited films and related to the configuration of our equipment. This behavior has been related to the deposition mechanism: at low pressure (below 1.2 mTorr), the deposition is mainly controlled, by ion bombardment, leading to high compressive residual stress. On the other hand, at high pressure (above 1.4 mTorr) the mechanism of $\mathrm{SiN}_{x}$ film formation resulted in the combination of a weaker effect of ion bombardment and coalescence between neighboring islands at the subsurface of the film, which leads first to a lower compressive stress, and second to a weak tensile strain generation.

The same behavior has been observed for all types of films deposited with our equipment, i.e., silicon dioxide and hydrogenated silicon films: residual stresses close to zero are obtained for films deposited in the pressure range 1.2-1.5 mTorr. This versatility has been successfully used for the deposition of $\mathrm{Si} / \mathrm{SiO}_{2}$ Bragg mirrors involved in the fabrication of tunable photodetectors ${ }^{51}$ based on III-V materials, for the infrared region.

\section{ACKNOWLEDGMENTS}

AFM measurements were performed at the "Institut de Recherche sur la Catalyse" (IRC) in Villeurbanne (France) by C. Deranlot. M.P.B. is particularly grateful to Dr. G. Grenet for insightful comments and critical reading of the manuscript. F. Karolak and J.B. Goure are gratefully acknowledged for etching experiments and technical assistance. Thanks are due to B. Agius and M. C. Hugon for providing $2 \mathrm{in}$. silicon substrates suitable for interferometry.

${ }^{1}$ D. G. Park et al., J. Vac. Sci. Technol. B 14, 2674 (1996).

${ }^{2}$ S. Garcia, I. Martil, G. Gonzalez Diaz, E. Castan, S. Duenas, and M. Fernandez, J. Appl. Phys. 83, 332 (1998).

${ }^{3}$ S. Sitbon, M. C. Hugon, B. Agius, F. Abel, J. L. Courant, and M. Puech, J. Vac. Sci. Technol. A 13, 2900 (1995)

${ }^{4}$ S. Matsuo, in Handbook of Thin Films Deposition Processes and Techniques, edited by K. K Schuegraf (Noyes, Park Ridge, NJ, 1988), p. 147.

${ }^{5}$ A. Shintani, S. Sugaki, and H. Nakashima, J. Appl. Phys. 51, 4197 (1980).

${ }^{6}$ A. Fourrier, A. Bosseboeuf, D. Bouchier, and G. Gautherin, Jpn. J. Appl. Phys., Part 1 30, 1469 (1991).

${ }^{7}$ H. Takahashi, H. Nagata, H. Kataoka, and H. Takai, J. Mater. Res. 10, 2736 (1995).

${ }^{8}$ J. E. Klemberg-Sapieha et al., J. Vac. Sci. Technol. A 14, 2775 (1996).

${ }^{9}$ J. H. Kim and K. W. Chung, J. Appl. Phys. 83, 5831 (1998).

${ }^{10}$ J. Ashley Taylor, J. Vac. Sci. Technol. A 9, 2464 (1991).

${ }^{11}$ J. G. E. Gardeniers, H. A. C. Tilmans, and C. C. G. Visser, J. Vac. Sci. Technol. A 14, 2879 (1996).

${ }^{12}$ A. G. Noskov et al., Thin Solid Films 162, 129 (1988).

${ }^{13}$ L. Shi et al., J. Vac. Sci. Technol. A 14, 471 (1996).

${ }^{14}$ P. Temple-Boyer, C. Rossi, E. Saint-Etienne, and E. Scheid, J. Vac. Sci. Technol. A 16, 2003 (1998).

${ }^{15}$ R. M. Kubacki, IEEE Trans. Compon., Packag. Manuf. Technol., Part A 18, 471 (1995).

${ }^{16}$ J. Ahn and K. Suzuki, Appl. Phys. Lett. 64, 3249 (1994).

${ }^{17}$ M. Maeda and K. Ikeda, J. Appl. Phys. 83, 3865 (1998).

${ }^{18}$ F. Delmotte, M. C. Hugon, B. Agius, and J. L. Courant, J. Vac. Sci. Technol. B 15, 1919 (1997).

${ }^{19}$ W. J. Dauksher et al., J. Vac. Sci. Technol. B 15, 2232 (1997). 
${ }^{20}$ P. J. French, P. M. Sarro, R. Mallée, E. J. M. Fakkeldij, and R. F. Wolffenbuttel, Sens. Actuators, A 58, 149 (1997).

${ }^{21}$ M. Stadtmüeller, J. Electrochem. Soc. 139, 3669 (1992).

${ }^{22}$ S. Habermehl, J. Appl. Phys. 83, 4672 (1998).

${ }^{23}$ T. M. Klein, T. M. Anderson, A. I. Chowdhury, and G. N. Parsons, J. Vac. Sci. Technol. A 17, 108 (1999).

${ }^{24}$ R. C. Cammarata, J. Electron. Mater. 26, 966 (1997).

${ }^{25}$ U. Geyer, U. Von Hülsen, and P. Thiyagarajan, Appl. Phys. Lett. 70, 1691 (1997).

${ }^{26}$ T. J. Vink, M. A. J. Somers, J. L. C. Daams, and A. G. Dirks, J. Appl. Phys. 70, 4301 (1991).

${ }^{27}$ S. P. Kim and S. K. Choi, Thin Solid Films 379, 259 (2000).

${ }^{28}$ J. Yu, J. G. Kim, J. O. Chung, and D. H. Cho, J. Appl. Phys. 88, 1688 (2000).

${ }^{29}$ B. W. Sheldon, K. H. A. Lau, and A. Rajamani, J. Appl. Phys. 90, 5097 (2001).

${ }^{30}$ J. H. Jeong, D. Kwon, and Y. J. Baik, J. Appl. Phys. 91, 6333 (2002).

${ }^{31}$ D. Landheer, K. Rajseh, D. Masson, J. E. Hulse, G. I. Sproule, and T. Quance, J. Vac. Sci. Technol. A 16, 2931 (1998).

${ }^{32}$ M. Lapeyrade, M. P. Besland, C. Meva'a, A. Sibaï, and G. Hollinger, J. Vac. Sci. Technol. A 17, 433 (1999).

${ }^{33}$ M. F. Lambrinos, M. P. Besland, A. Gagnaire, P. Louis, S. Callard, and J. Joseph, J. Electrochem. Soc. 144, 2086 (1997).

${ }^{34}$ S. Callard, A. Gagnaire, M. P. Besland, and J. Joseph, Thin Solid Films 313-314, 479 (1998).

${ }^{35}$ L. B. Freund, J. A. Floro, and E. Chason, Appl. Phys. Lett. 74, 1987 (1999).
${ }^{36}$ T. E. Retajczyk, and A. K. Sinha, Thin Solid Films 70, 241 (1980).

${ }^{37}$ G. Moulard, G. Contoux, G. Motyl, G. Gardet, and M. Courbon, J. Vac. Sci. Technol. A 16, 736 (1998).

${ }^{38}$ I. Sugimoto and S. Nakano, Appl. Phys. Lett. 62, 2116 (1993).

${ }^{39}$ R. C. Cammarata, T. M. Trimble, and D. J. Srolovitz, J. Mater. Res. 15, 2468 (2000).

${ }^{40}$ M. A. Bachlechner et al., Appl. Phys. Lett. 72, 1969 (1998).

${ }^{41}$ M. Copel, P. R. Varekamp, D. W. Kisker, F. R. McFeely, K. E. Litz, and M. M. Banaszak Holl, Appl. Phys. Lett. 74, 1830 (1999).

${ }^{42}$ N. Suzuki, T. Yoshikawa, K. Masu, K. Tsubouchi, and N. Mikoshiba, Jpn. J. Appl. Phys., Part 2 28, L2316 (1989).

${ }^{43}$ J. A. Theil, S. V. Hattangady, and G. Lucovsky, J. Vac. Sci. Technol. A 10, 719 (1992).

${ }^{44}$ H. Leplan, B. Geenen, J. Y. Robic, and Y. Pauleau, J. Appl. Phys. 78, 962 (1995).

${ }^{45}$ Y. Park et al., Appl. Phys. Lett. 75, 3811 (1999).

${ }^{46}$ J. A. Thornton, J. Tabock, and D. W. Hoffman, Thin Solid Films 64, 111 (1979).

${ }^{47}$ L. B. Freund and E. Chason, J. Appl. Phys. 89, 4866 (2001).

${ }^{48}$ S. G. Mayr and K. Samwer, Phys. Rev. Lett. 87, 036105 (2001).

${ }^{49}$ J. Yota, J. Hander, and A. A. Saleh, J. Vac. Sci. Technol. A 18, 372 (2000).

${ }^{50}$ Y. Kim and S. H. Choo, Thin Solid Films 394, 283 (2001).

${ }^{51}$ S. Jourba, M.-P. Besland, M. Gendry, M. Garrigues, J.-L. Leclercq, P. Rojo-Romeo, P. Viktorovitch, S. Cortial, X. Hugon, and C. Pautet, Electron. Lett. 35, 1272 (1999). 